\title{
Article \\ Multiscale Interactive Processes Underlying the Heavy Rainstorm Associated with a Landfalling Atmospheric River
}

\author{
Zhuang Zhang ${ }^{1}$ and X. San Liang ${ }^{2,3,4, *}$ \\ 1 School of Atmospheric Sciences, Nanjing University of Information Science and Technology, \\ Nanjing 210044, China; zhangz@nuist.edu.cn \\ 2 Department of Atmospheric \& Oceanic Sciences, Institute of Atmospheric Sciences, Fudan University, \\ Shanghai 200438, China \\ 3 IRDR ICoE on Risk Interconnectivity and Governance on Weather/Climate Extremes Impact and Public \\ Health, Fudan University, Shanghai 200438, China \\ 4 Shanghai Qi Zhi Institute (Andrew C. Yao Institute for Artificial Intelligence), Shanghai 200232, China \\ * Correspondence: xsliang@fudan.edu.cn
}

Citation: Zhang, Z.; Liang, X.S. Multiscale Interactive Processes Underlying the Heavy Rainstorm Associated with a Landfalling Atmospheric River. Atmosphere 2022, 13, 29. https://doi.org/10.3390/ atmos13010029

Academic Editors: Mengqian Lu and Mengxin Pan

Received: 7 December 2021

Accepted: 22 December 2021

Published: 26 December 2021

Publisher's Note: MDPI stays neutral with regard to jurisdictional claims in published maps and institutional affiliations.

Copyright: (c) 2021 by the authors. Licensee MDPI, Basel, Switzerland. This article is an open access article distributed under the terms and conditions of the Creative Commons Attribution (CC BY) license (https:// creativecommons.org/licenses/by/ $4.0 /)$.

\begin{abstract}
The heavy precipitation in Northern California-brought about by a landfalling atmospheric river (AR) on 25-27 February 2019-is investigated for an understanding of the underlying dynamical processes. By the peaks in hourly accumulation, this rainstorm can be divided into two stages (Stage I and Stage II). Using a recently developed multiscale analysis methodology, i.e., multiscale window transform (MWT), and the MWT-based theory of canonical transfer, the original fields are reconstructed onto three scale windows, namely, the background flow, synoptic-scale and mesoscale windows, and the interactions among them are henceforth investigated. In both stages, the development of the precipitation is attributed to a vigorous buoyancy conversion and latent heating, and besides, the instability of the background flow. In Stage I, the instability is baroclinic, while in Stage II, it is barotropic. Interestingly, in Stage I, the mesoscale kinetic energy is transferred to the background flow where it is stored, and is released back in Stage II to the mesoscale window again, triggering intense precipitation.
\end{abstract}

Keywords: rainstorm; atmospheric river; multiscale window transform; canonical transfer; barotropic instability; baroclinic instability

\section{Introduction}

As an elongated and transient plume of strong horizontal water vapor transport, atmospheric rivers (ARs) not only are essential to the global water cycle [1,2], but also play an important role in the occurrence of extreme precipitation and hydrological hazards [3-5]. Particularly, landfalling ARs frequently give rise to extreme rainfall and flash flooding when they meet the topography [6-12]. Due to the linkage to different natural hazards, ARs have received more and more attention in recent years [13-17].

From the perspective of water supply, most ARs are beneficial because they can supply water vapor to alleviate the drought. For instance, Kim [18] found that ARs can account for over $70 \%$ of the winter precipitation in western United States. Dettinger et al. [3] reported that ARs may make contributions to more than $50 \%$ of the annual runoff over the west coast of North America. In other regions, similar results are obtained. However, in terms of hazardous weather, a few extreme ARs are damaging, incurring extreme rainfall. Numerous studies have demonstrated that the frequency of ARs is highly correlated to that of extreme precipitation events or flooding $[3,4,6,10,19,20]$. In Western Europe (e.g., Britain and Germany), ARs can increase the occurrence of flooding events by $40 \%$, even up to $80 \%$ in some areas [4]. In East Asia, Kamae et al. [19] concluded that 20 90\% of extreme rainfall events are associated with ARs during spring, summer and autumn. Kim et al. [11] further stated that the relationship between ARs and precipitation varies with seasons and regions. 
The role of landfalling ARs in flooding on the Russian River was examined [6]. It is found that AR conditions are present in all seven floods and trigger heavy rainfalls. It is well understood that ARs can transport abundant water vapor, incurring precipitation [21,22]. Apart from moisture, dynamic conditions are also critical to trigger precipitation. This aspect, however, has received far less attention in studying rainstorm events brought by landfalling ARs. Inspired by Ralph et al. [23] who examined the impact of systems with different scales from planetary to mesoscale on ARs, we intended to investigate the heavy rainfall associated with landfalling ARs from the view of multiscale interactions, in order to clarify how dynamic processes force the precipitation related to them.

Recently, a theory [24] and methodology [25] for multiscale interaction analysis have been systematically developed. The purpose of this study was to explore the multiscale interactions underlying a heavy rainfall event in Northern California incurred by a landfalling AR on 25-27 February 2019 (see http:/ / floodlist.com/america/usa/usa-california-russianriver-february-2019 for details, accessed on 10 September 2021). This rest of the paper is organized as follows: We briefly introduce the data in Section 2.1 and the methodology for the analysis in Section 2.2. In Section 3, this rainstorm is briefly reviewed. Presented in Sections 4 and 5 are the major results. Section 6 summarizes the study.

\section{Data and Methodology}

2.1. Data

We utilized for this study the high-resolution data from the ERA5 reanalysis sets [26], with a temporal and horizontal resolution of $1 \mathrm{~h}$ and $0.25^{\circ}$, respectively. The variables include geopotential $(\phi)$, temperature $(T)$, three-dimensional wind vector $(u, v, \omega)$ and specific humidity $(q)$, extending from $10^{\circ} \mathrm{N}$ to $60^{\circ} \mathrm{N}$, from $180^{\circ} \mathrm{W}$ to $100^{\circ} \mathrm{W}$. Vertically, there are 25 levels from 1000 to $50 \mathrm{hPa}$, with an interval of $25 \mathrm{hPa}$ under $750 \mathrm{hPa}$ and $50 \mathrm{hPa}$ above $750 \mathrm{hPa}$. The temporal coverage is from 14 January to 9 April 2019.

\subsection{Localized Multiscale Energetics Analysis}

In the 1950s, Lorenz [27] derived the equations for the zonal-mean and eddy energy based on the Reynolds decomposition with respect to longitudes. This very successful and useful formalism, however, cannot reveal the zonally variable multiscale energetics. If the Reynolds decomposition with respect to time is performed, the resulting average and perturbation energies are invariant in time. To overcome the difficulty, during the past decades filtering has been widely utilized to fulfill the scale decomposition. In the literature, it is a common practice to write a multiscale energy simply as the square of the corresponding reconstructed (filtered) field (up to some constant factor). However, it is conceptually wrong to represent multiscale energy with filtered fields as clarified by Liang [24] since multiscale energy is a concept in phase space (e.g., the square of a Fourier coefficient with a Fourier transform) rather than in physical space. It is absolutely not equal to the square of the filtered/reconstructed variable. The phase space representation is related to its physical space counterpart through a renowned theorem called Parseval Relation [24,25].

To faithfully represent the time-varying multiscale energetics, Liang and Anderson [25] developed a new functional apparatus called multiscale window transform (MWT). With MWT, a function space is decomposed into a direct sum of several mutually orthogonal subspaces, each with an exclusive range of scales. Such a subspace is called a "scale window" [25].

For example, in a three-scale decomposition, $u(t)$ can be decomposed as

$$
u(t)=u^{\sim 0}(t)+u^{\sim 1}(t)+u^{\sim 2}(t)
$$

where $u^{\sim 0}(t), u^{\sim 1}(t)$ and $u^{\sim 2}(t)$ stand for the low-pass, band-pass, and high-pass filtered component. Different from traditional filters, MWT can yield not only the filtered fields, but also the transform coefficients $\widehat{u}_{n}^{\sim \omega}$ ( $\omega$ denotes any scale window, $n$ stands for any time step), which allow for a representation of multiscale energies. By a theorem called 
"property of marginalization", Liang and Anderson [25] proved that the energy on scale window $\omega$ can be expressed as $\left(\widehat{u}_{n}^{\sim}\right)^{2}$ (up to some factor). Note that this is not equal to the square of the filtered variable $u^{\sim \omega}(t)$.

In the framework of MWT, the kinetic energy (KE) and available potential energy (APE) on scale window $\omega$ at any time step $n$, denoted by $K_{n}^{\mathscr{Q}}$ and $A_{n}^{\omega}$ can be expressed as:

$$
\begin{gathered}
K_{n}^{\mathscr{W}}=\frac{1}{2}{\widehat{\left(v_{h}\right)_{n}}}^{\sim \mathcal{W}} \cdot{\widehat{\left(v_{h}\right)_{n}}}_{n}^{\mathcal{W}} \\
A_{n}^{\mathscr{W}}=\frac{1}{2} c\left(\widehat{T}_{n}^{\sim \mathcal{W}}\right)^{2}
\end{gathered}
$$

where $v_{h}=(u, v)$ is the horizontal wind, $T$ is the temperature departure from the vertical profile of the background temperature (averaged over time and area), $c=\frac{g}{\bar{T}\left(g / c_{p}-L\right)}$ is a constant which is proportional to the buoyancy frequency ( $g$ is the gravitational acceleration, $c_{p}$ is the specific heat at constant pressure, $\bar{T}$ is the background temperature, and $L$ is the lapse rate). Based on the primitive equations, Liang [24] obtained the equations governing the kinetic energy (KE) and available potential energy (APE) on scale window $\omega(\omega=0,1,2)$ (the subscript $n$ is omitted for brevity):

$$
\begin{aligned}
& \frac{\partial K^{\omega}}{\partial t}=\underbrace{-\nabla \cdot\left[\frac{1}{2}{\widehat{\left(v v_{h}\right)}}^{\sim \omega} \cdot \widehat{v}_{h}^{\sim \omega}\right]}_{-\nabla \cdot Q_{K}^{\omega}} \underbrace{-\nabla \cdot\left(\widehat{v}^{\sim \omega} \widehat{\phi}^{\sim \omega}\right)}_{-\nabla \cdot Q_{P}^{\omega}}+\underbrace{\frac{1}{2}\left[{\widehat{\left(v v_{h}\right)}}^{\sim \omega}: \nabla \widehat{v}_{h}^{\sim \omega}-\nabla \cdot \widehat{\left(v v_{h}\right)}{ }^{\sim \omega} \cdot \widehat{v}_{h}^{\sim \omega}\right]}_{\Gamma_{K}^{\infty}}-\underbrace{\widehat{\omega}^{\sim \omega} \widehat{\alpha}^{\sim \omega}}_{b^{\infty}}+F_{K}^{\omega}
\end{aligned}
$$

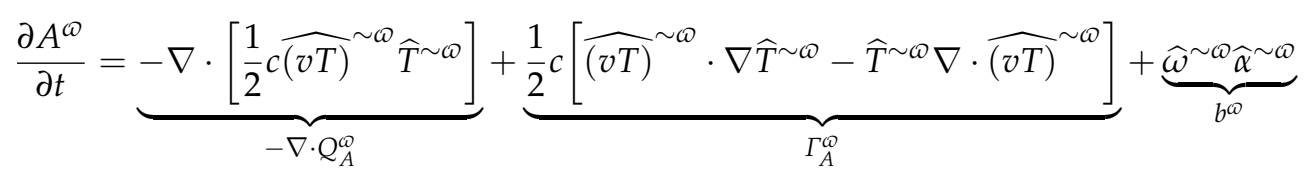

$$
\begin{aligned}
& +\underbrace{\frac{1}{2} \widehat{T}^{\sim \omega} \widehat{(\omega T)} \sim \mathcal{D} \frac{\partial c}{\partial p}+\frac{1}{\bar{T}} \widehat{T}^{\sim \omega} \widehat{(\omega \alpha)} \sim \mathcal{\omega}}_{S_{A}^{\infty}}+F_{A}^{\infty}
\end{aligned}
$$

where $v=(u, v, \omega)$ is the $3 \mathrm{D}$ wind field, $\alpha$ is the specific volume. The operator (:) is defined such that $(\boldsymbol{A B}):(\boldsymbol{C D})=(\boldsymbol{A} \cdot \boldsymbol{C})(\boldsymbol{B} \cdot \boldsymbol{D})$ for two dyadic products $A \boldsymbol{B}$ and $\boldsymbol{C D}$. Other notations are conventional. In Equation (4), $-\nabla \cdot Q_{K}^{\mathscr{Q}}$ is the spatial transport term of KE

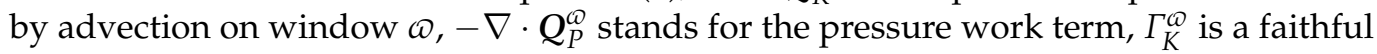
representation of the transfer, i.e., canonical transfer, of KE to window $\mathcal{\omega}$ from other windows, $b^{\omega}$ denotes the buoyancy conversion between KE and APE on window $\omega$, and $F_{K}^{Q}$ is the frictional dissipation term, which is obtained by evaluating the residual in the balance. In Equation (5), $-\nabla \cdot Q_{A}^{\omega}$ is the spatial transport term of APE by advection on window $\omega, \Gamma_{A}^{\mathscr{\omega}}$ as above represents the canonical transfer of APE to window $\omega$ from other windows, and $F_{A}^{\infty}$ is the diabatic heating term.

As derived by Liang [24], the diabatic heating term $F_{A}^{\Phi}$ is expressed as $F_{A}^{\infty}=\frac{c}{c_{p}} \widehat{T} \sim \omega \widehat{\dot{q}_{\text {net }}} \sim \omega$ $\left(\dot{q}_{\text {net }}\right.$ stands for the heating rate from all diabatic terms, including sensible heating, latent heating and radiation). To measure the latent heating from the phase transformation which is essential for precipitation, $\dot{q}_{n e t}$ is replaced with the latent heating rate $Q_{L}=-L_{v} \frac{d q}{d t}=-L_{v} F \omega$ following Shen et al. [28], Now the latent heating term $F_{L}^{\infty}$ can be calculated by

$$
F_{L}^{\mathscr{\omega}}=\frac{c L_{v}}{c_{p}} \widehat{T}^{\sim \mathcal{\omega}} \widehat{(-F \omega)}^{\sim \mathcal{W}}
$$

where $L_{v} \approx 2.5 \times 10^{6} \mathrm{~J} / \mathrm{kg}$ is the specific heat of condensation, $F=\frac{q T}{p}\left(\frac{L_{v} R_{d}-c_{p} R_{w} T}{c_{p} R_{w} T^{2}+q L_{v}^{2}}\right)$ the condensation function, $\omega$ the vertical velocity, $q$ specific humidity, $R_{d} \approx 287.058 \mathrm{~J} / \mathrm{kg} / \mathrm{K}$ 
the specific gas constant for dry air, and $R_{w} \approx 461.520 \mathrm{~J} / \mathrm{kg} / \mathrm{K}$ the specific constant for water vapor).

Above we have introduced the concept of canonical transfer. It is an expression of energy transfer which is quite different from the traditional ones. As rigorously proved in Liang [24], a canonical transfer faithfully represents the inter-scale energy transfer because it automatically meets the criterion of energy conservation, while the traditional ones do not. Specifically, it satisfies

$$
\sum_{\omega} \sum_{n} \Gamma_{n}^{\mathscr{W}}=0
$$

This means that it is a process such that energy is only redistributed among the scale windows, and is conserved as a whole. Canonical transfer gains its name in that it has a Lie bracket form, reminiscent of the Poisson bracket in Hamiltonian dynamics. See Liang [24] for details.

As demonstrated by Liang and Robinson [29], the canonical transfer terms can be further analyzed to single out the transfers from one window, say, $\omega_{1}$, to another, say $\omega_{2}$. Notationally, we will henceforth write as $\Gamma^{\omega_{1} \rightarrow \omega_{2}}$. In a three-window framework as shown above, for example, $\Gamma_{K}^{0 \rightarrow 2}\left(\Gamma_{A}^{0 \rightarrow 2}\right)$ represents the canonical transfer of KE (APE) from the background-scale window to the mesoscale window. Likewise, $\Gamma_{K}^{1 \rightarrow 2}\left(\Gamma_{A}^{1 \rightarrow 2}\right)$ represents the canonical transfer of KE (APE) from the synoptic-scale window to the mesoscale window. Moreover, Liang and Robinson [30] proved that $\Gamma_{K}^{0 \rightarrow 2}\left(\Gamma_{A}^{0 \rightarrow 2}\right)$ corresponds to the barotropic (baroclinic) instability in the classical sense, if the values are positive.

So far, this theory has been widely applied to the studies of atmospheric and oceanic dynamics problems such as cold air outbreak [31], storm track [32], atmospheric blockings [33], tropical cyclogenesis [34], vortices over Tibet Plateau [35], Kuroshio Extension dynamics [36], to name a few. For more details, the reader is referred to Liang [24] and Liang and Anderson [25].

\section{Characteristics of the Heavy Rainfall}

As introduced in Section 1, this rainstorm was brought by a landfalling AR on 25-27 February 2019 in the Northern California. Figure 1a shows the 48-h accumulated rainfall during the period based on the hourly precipitation data from the ERA 5 dataset. The box marks the rainfall area $\left(38.5-43.5^{\circ} \mathrm{N}, 125-121^{\circ} \mathrm{W}\right)$, over which the area averaging is taken. As displayed in Figure 1b, there are two peaks in the trend of the hourly rainfall, respectively from 10 UTC 25 February to 18 UTC 25 February and from 18 UTC 26 February to 04 UTC 27 February. This indicates that the lifecycle of the heavy rain can be divided into two stages: Stage I (from 00 UTC 25 February to 00 UTC 26 February) and Stage II (from 12 UTC 26 February to 12 UTC 27 February).
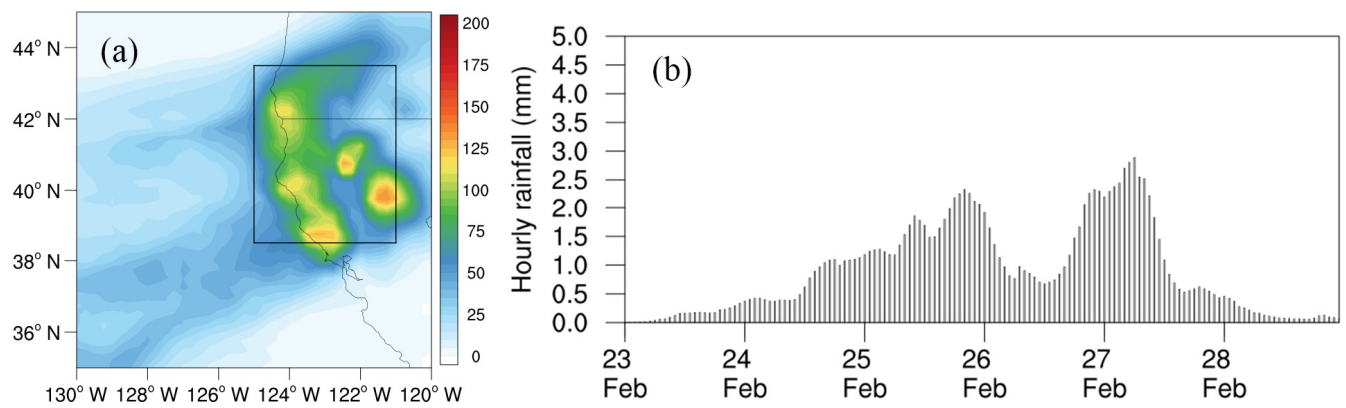

Figure 1. (a) The 48-h accumulated rainfall (in mm) during 25-27 February 2019. The rainfall area $\left(38.5-43.5^{\circ} \mathrm{N}, 125-121^{\circ} \mathrm{W}\right)$ is boxed. (b) Time series of the hourly rainfall averaged over the box in (a).

To examine the circulation pattern associated with this extreme precipitation, we plotted horizontal maps of the 850-hPa geopotential (contours) and the integrated water vapor transport from 1000 to $300 \mathrm{hPa}$ (IVT; shaded), as illustrated in Figure 2. Here, IVT is 
used to represent the AR, following the convention as used in previous studies [37,38]. At 06 UTC February 25 , there are two cyclonic centers at $850 \mathrm{hPa}$, located at $130^{\circ} \mathrm{W}(\mathrm{C} 1)$ and $150^{\circ}$ $\mathrm{W}(\mathrm{C} 2)$, respectively. During Stage I (Figure $2 \mathrm{a}-\mathrm{c}$ ), the landfalling AR at the west coast of Northern California is rather vigorous, with a maximum of IVT exceeding $700 \mathrm{~kg} \mathrm{~m}^{-1} \mathrm{~s}^{-1}$. Afterwards, it is weakened (not shown). It revives during Stage II (Figure $2 \mathrm{~d}-\mathrm{f}$ ), becoming much stronger than Stage I. It should be noted that the AR is accompanied by C1 during Stage I, whereas it is close to C2 during Stage II.
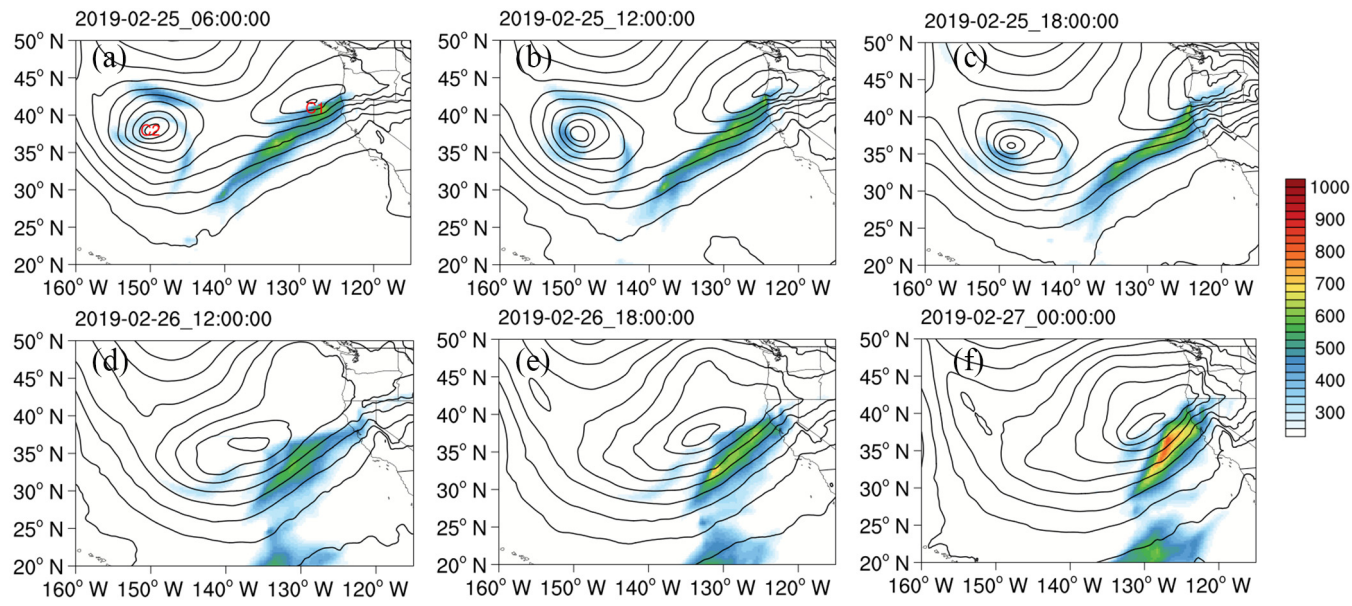

Figure 2. Maps of the 850-hPa geopotential (contours; in $\mathrm{m}^{2} \mathrm{~s}^{-2}$ ) and IVT (shadings; in $\mathrm{kg} \mathrm{m}^{-1} \mathrm{~s}^{-1}$ ): (a) 25 February at 06:00 UTC, (b) 25 February at 12:00 UTC, (c) 25 February at 18:00 UTC, (d) 26 February at 12:00 UTC, (e) 26 February at 18:00 UTC and (f) 27 February at 00:00 UTC. The extratropical cyclones at $130^{\circ} \mathrm{W}$ and $150^{\circ} \mathrm{W}$ are respectively labeled as "C1" ad "C2" in (a).

The difference between Stage I and Stage II is further compared in terms of rainfall area. Figure 3 presents the 24-h accumulated rainfall distributions during Stage I and Stage II, with the areas respectively boxed. During Stage I, it is seen located to the north of $40^{\circ}$ $\mathrm{N}$ (box in Figure 3a), whereas during Stage II, it is predominantly situated south of the latitude (box in Figure 3b).
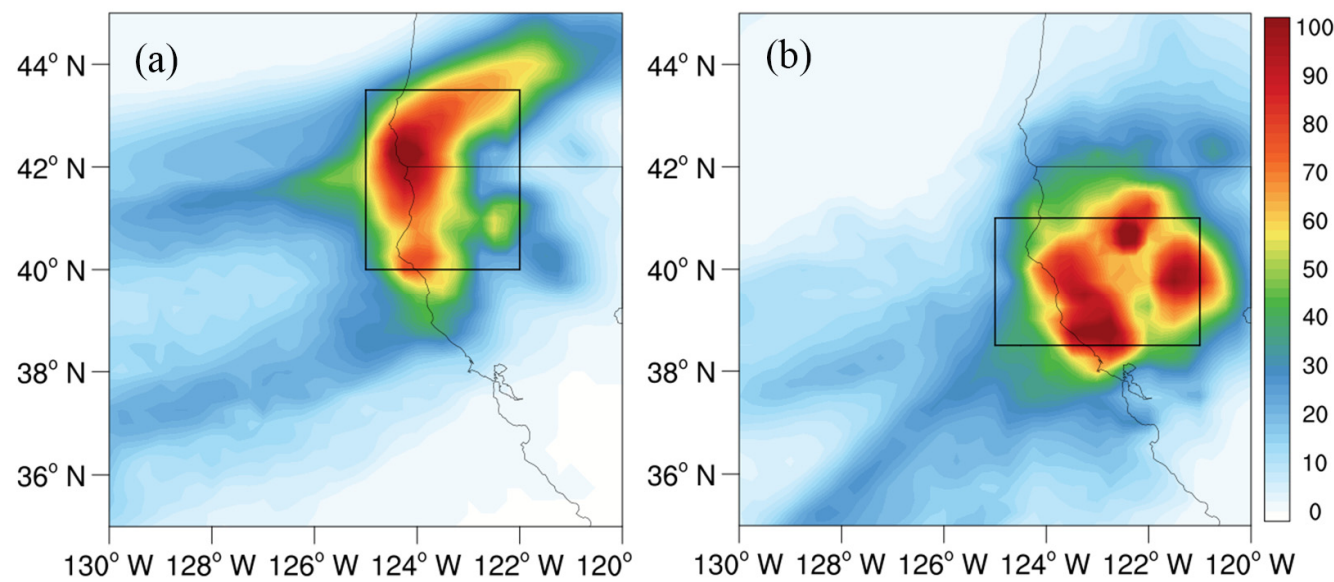

Figure 3. The distribution of the 24-h accumulated precipitation: (a) during Stage I (from 25 February 00:00 UTC, to 26 February 00:00 UTC) and (b) during Stage II (from 26 February 12:00 UTC, to 27 February 12:00 UTC). The heavy rain area is marked by the box: (a) Stage I and (b) Stage II.

\section{Scale Decomposition}

To investigate the multiscale interactions underlying the rainstorm, we firstly applied MWT to fulfill scale decomposition. Considering the heavy rain is attributed to the AR within a synoptic scale $[1,39,40]$, two cutoff periods are required to demarcate three scale 
windows in this study, namely, the background flow window, the synoptic-scale window and the mesoscale window. For easy reference, $\omega=0,1,2$ is used to denote the three windows, respectively. The wavelet spectrum analysis [41] is employed to define these cutoff periods/scale levels, which mark the bounds for the windows. Since ARs with strong horizontal water vapor transport take place below $3 \mathrm{~km} \mathrm{[42],} \mathrm{here,} \mathrm{the} \mathrm{850-hPa} \mathrm{specific}$ humidity is used for spectral analysis. Figure $4 \mathrm{~b}$ presents the wavelet power spectrum of the $850-\mathrm{hPa}$ specific humidity $(q)$ in Venado $\left(38.5^{\circ} \mathrm{N}, 123^{\circ} \mathrm{W}\right)$, California, with a maximum precipitation of $500 \mathrm{~mm}$ within $48 \mathrm{~h}$. One observation is that there are three dominant peaks of the spectra, corresponding to periods longer than $256 \mathrm{~h}$, between 32 and $256 \mathrm{~h}$, and shorter than $32 \mathrm{~h}$. Based on this, the cutoff periods are set to be 32 and $256 \mathrm{~h}$, respectively. That is to say that processes with periods longer than $256 \mathrm{~h}$ are defined as the background flow window, those with periods between 32 and $256 \mathrm{~h}$ are treated as the synoptic-scale window (ARs and extratropical cyclones are included), and those with periods shorter than $32 \mathrm{~h}$ are included in the mesoscale window, such as mesoscale processes associated with heavy rain.

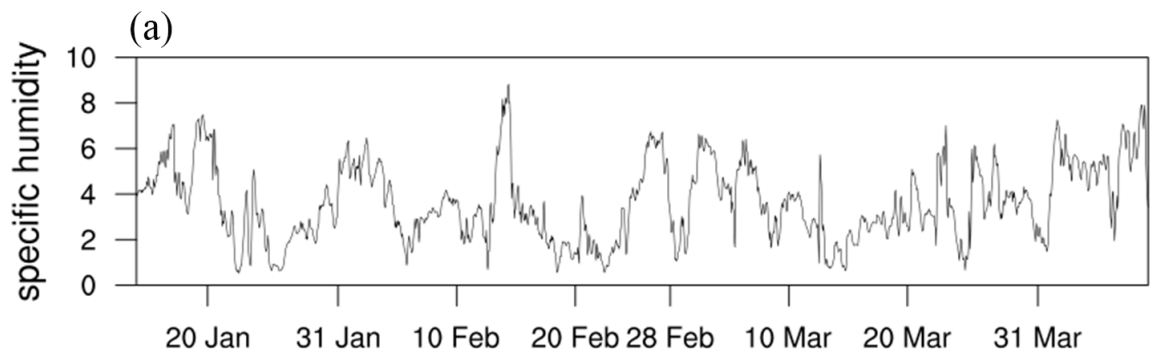

(b)

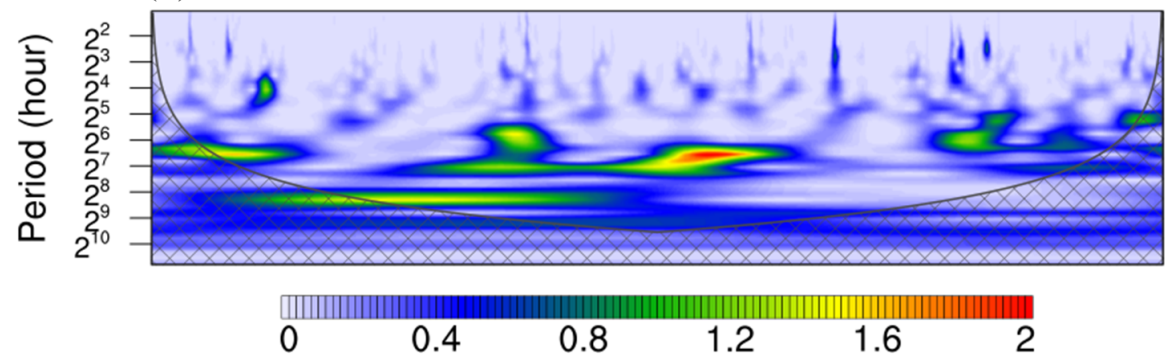

Figure 4. (a) Time series of the $850-\mathrm{hPa}$ specific humidity ( $q$, in $\mathrm{g} / \mathrm{kg})$ in Venado $\left(38.5^{\circ} \mathrm{N}, 123^{\circ} \mathrm{W}\right)$, California. (b) The wavelet power spectrum of (a). The left axis is the period (in hour), and the bottom axis is time.

With the MWT setting, the original total fields are reconstructed onto three scale windows. On the background flow window, there is a nonstationary high-level jet between $40^{\circ}$ to $50^{\circ} \mathrm{N}$ at $300 \mathrm{hPa}$ (not shown). Figure 5 depicts the maps of the synoptic-scale geopotential anomaly (contours) and specific humidity (shadings) at $850 \mathrm{hPa}$. One common observation is that there is a long and narrow belt of enhanced values of the synoptic-scale specific humidity $\left(q^{\sim 1}\right)$ between the cyclone and anticyclone, in accordance with the synoptic-scale pattern associated with ARs [7,38]. This indicates that ARs and extratropical cyclones or anticyclones are well separated from the original field through an MWT application. 

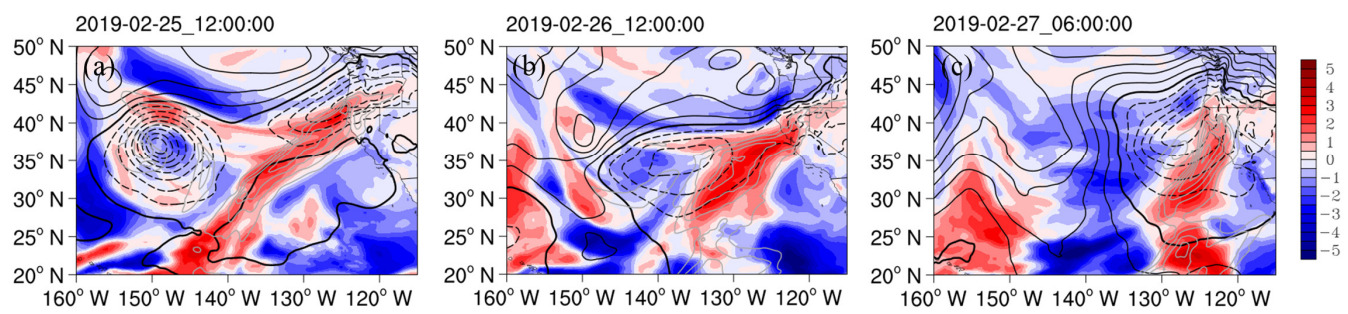

Figure 5. Maps of the synoptic geopotential anomaly $\left(\phi^{\sim 1}\right.$; contours; in $\left.\mathrm{m}^{2} \mathrm{~s}^{-2}\right)$ and specific humidity ( $q^{\sim 1}$; shadings; in g/kg) at $850 \mathrm{hPa}$ (a) 25 February at 12:00 UTC, (b) 26 February at 12:00 UTC, (c) 27 February at 06:00 UTC. Gray contours denote ARs (IVT $>=250 \mathrm{~kg} \mathrm{~m}^{-1} \mathrm{~s}^{-1}$ ) with an interval of 100. The interval of black contours is 150 (solid lines for positive values, dashed lines for negative values, and bold line for zero value).

To determine whether signals of the rainstorm are effectively separated or not, we plotted maps of the mesoscale $\mathrm{KE}\left(\mathrm{K}^{2}\right)$ and reconstructed mesoscale vertical velocity $\left(-\omega^{\sim 2}\right)$ averaged vertically from $900 \mathrm{hPa}$ to $300 \mathrm{hPa}$, as shown in Figure 6b,d. One can see that where the hourly precipitation is strong, both $\mathrm{KE}$ and ascending motion on the mesoscale window are enhanced. This collocation justifies our scale decomposition, indicating that signals of the rainstorm can be extracted from the original field and represented with the $\mathrm{KE}$ and vertical velocity on the mesoscale window.
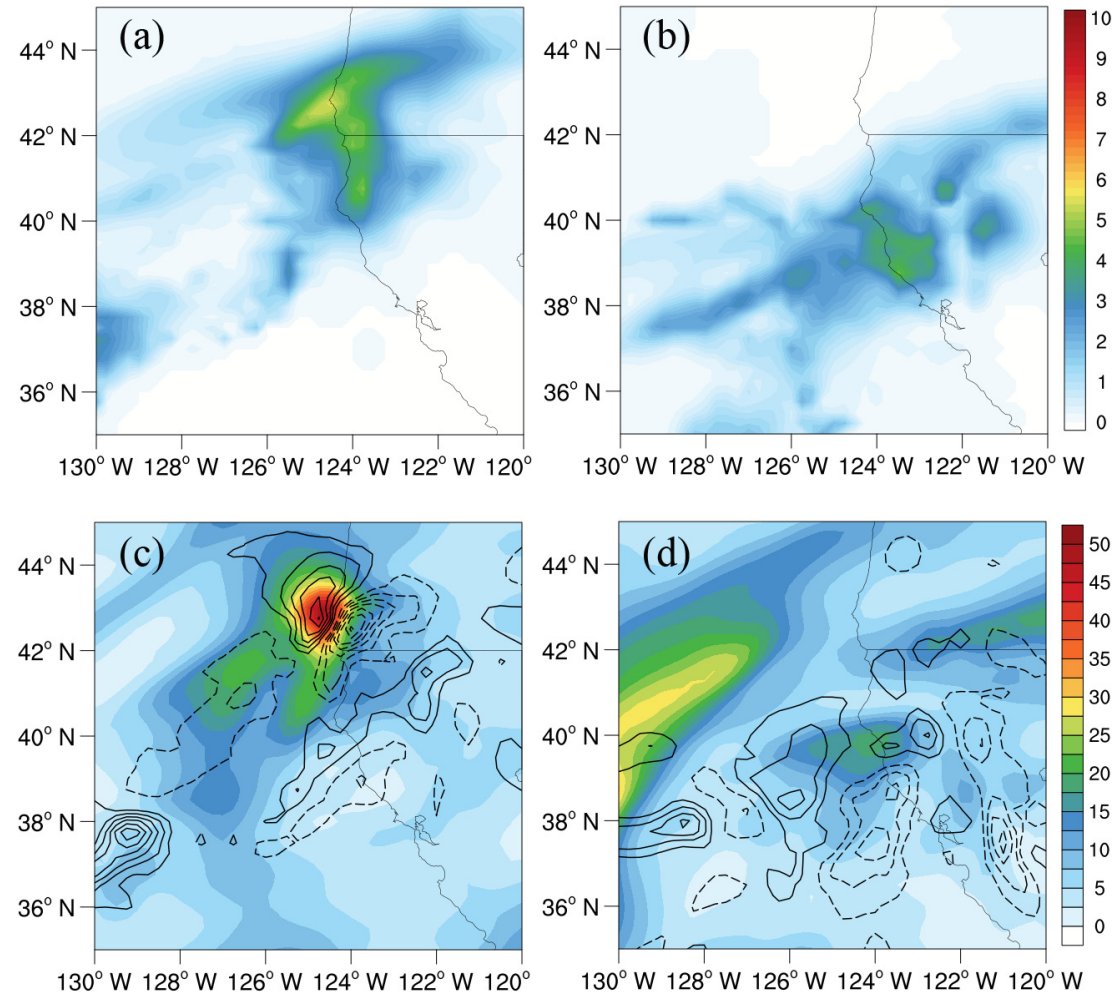

Figure 6. Spatial distributions of the hourly rainfall (in mm): (a) 25 February 09:00-10:00 UTC and (b) 26 February 17:00-18:00 UTC. Horizontal maps of the mesoscale KE $\left(K^{2}\right.$; shadings; in $\left.\mathrm{m}^{2} \mathrm{~s}^{-2}\right)$ and vertical velocity ( $-\omega^{\sim 2}$; contours; in Pa/s) averaged vertically from 900 to $300 \mathrm{hPa}$ : (c) 25 February 10:00 UTC and (d) 26 February 18:00 UTC. Solid contours represent the ascending motion with an interval of 0.2 (the contour with zero value is not drawn).

\section{Dynamics Underlying the Extreme Precipitation}

In Section 4, the synoptic systems (ARs, extratropical cyclones or anticyclones) and mesoscale processes associated with the rainstorm are appropriately decomposed from the original field. Based on this, we investigated the multiscale interaction behind the extreme 
AR-related precipitation, which are quantitatively expressed in terms of the canonical transfers across different scale windows and buoyancy conversions. As there are two different stages, we will investigate the dynamical processes independently for Stage I (from 25 February at 00 UTC to 26 February at 00 UTC 26) and Stage II (from 26 February at 12:00 UTC to 27 February at 12:00 UTC). Two moments, 25 February at 10:00 UTC and 26 February at 18:00 UTC, are chosen to render their respective representative results. For other moments, the patterns are similar.

\subsection{Stage I}

Figure 7 illustrates horizontal distributions of the barotropic transfers $\left(\Gamma_{K}^{0 \rightarrow 2}, \Gamma_{K}^{1 \rightarrow 2}\right)$, baroclinic transfer $\left(\Gamma_{A}^{0 \rightarrow 2}\right)$, and buoyancy conversion $\left(-b^{2}\right)$ on the mesoscale window averaged from 900 to $300 \mathrm{hPa}$ on 25 February at 10:00 UTC (The baroclinic transfer $\Gamma_{A}^{1 \rightarrow 2}$ is not shown because the value by comparison is negligible). The rainfall area for Stage I is marked by the box in Figure 7a. Contours of the mesoscale vertical velocity $\left(-\omega^{\sim 2}\right)$ are added in Figure 7. For the main body of the ascending motion over the box in Figure 7a, the large negative pool of $\Gamma_{K}^{0 \rightarrow 2}$ corresponds well to the vigorous ascending motion (solid contours), whereas the positive values are confined within the descending motion area (dashed contours). In contrast, negative $\Gamma_{A}^{0 \rightarrow 2}$ are distributed within the descending motion region, and vice versa. Recall that a positive $\Gamma_{K}^{0 \rightarrow 2}\left(\Gamma_{A}^{0 \rightarrow 2}\right)$ indicates a barotropic (baroclinic) instability of the background flow (cf. Section 2.2). Over the ascending area, the atmosphere is hence barotropically stable, but baroclinically unstable, while over the descending area, it is baroclinically stable, but barotropically unstable. Another observation is that positive values of $-b^{2}$ are everywhere throughout the rainfall area, indicating that the mesoscale $\mathrm{APE}$ is converting to mesoscale KE throughout, despite the distinct instabilities.

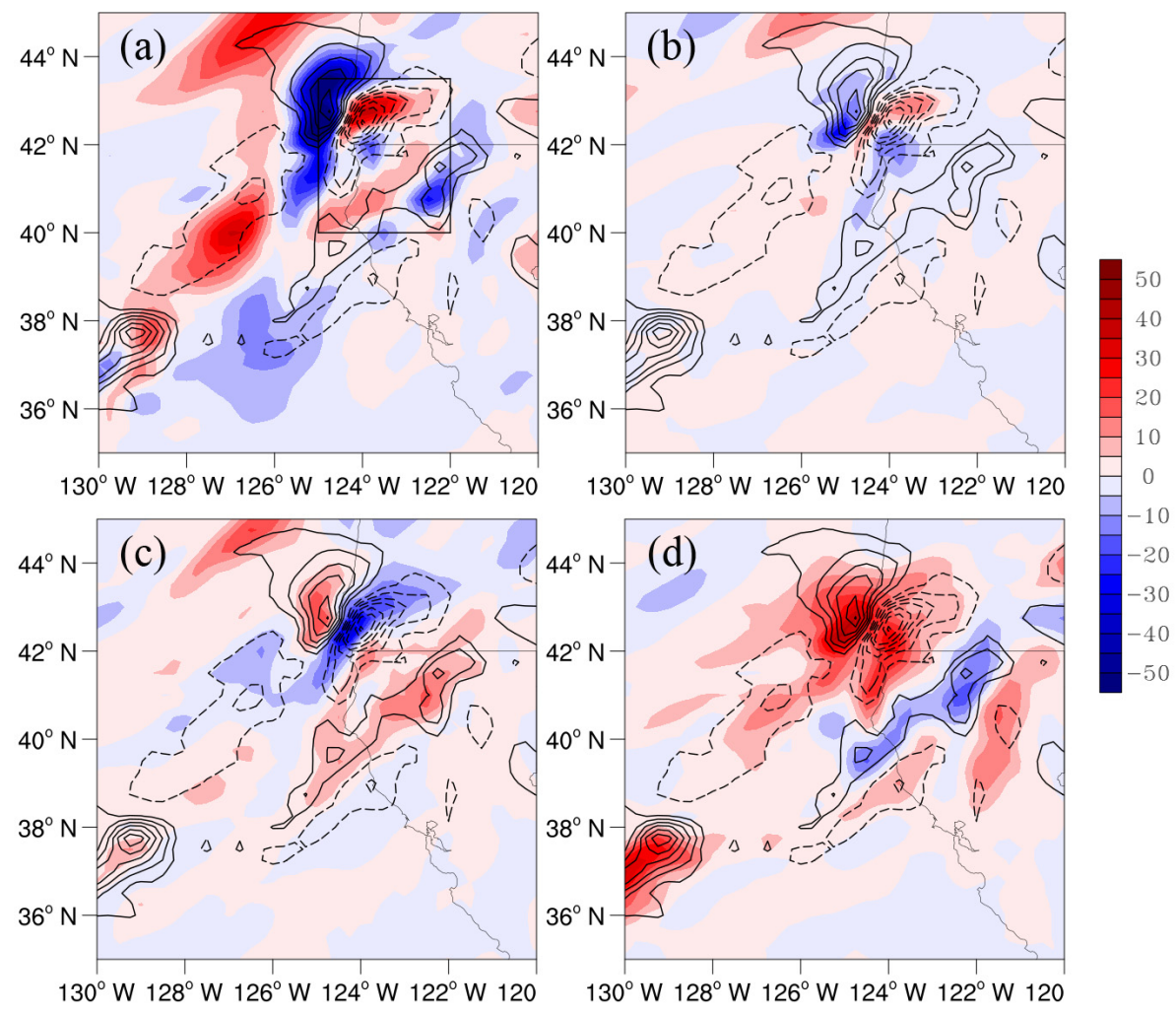

Figure 7. Horizontal distributions of the energetics (shadings; in $10^{-4} \mathrm{~m}^{2} \mathrm{~s}^{-3}$ ) and mesoscale vertical velocity ( $-\omega^{\sim 2}$; contours; in $\mathrm{Pa} / \mathrm{s}$ ) averaged vertically from 900 to $300 \mathrm{hPa}$ on 25 February at 10:00 UTC: (a) $\Gamma_{K}^{0 \rightarrow 2}$, (b) $\Gamma_{K}^{1 \rightarrow 2}$, (c) $\Gamma_{A}^{0 \rightarrow 2}$ and (d) $-b^{2}$. The box in (a) denotes the rainfall area during Stage I. Solid contours represent the ascending motion with an interval of 0.2 . 
To take a look at vertical structures of these dynamic processes, we drew the zonalvertical sectional distributions averaged over the latitudinal band $42^{\circ}-44^{\circ} \mathrm{N}$, and show them in Figure 8. At 10:00 UTC, 25 February the ascending motion (solid contours) develops to reach $400 \mathrm{hPa}$. The canonical transfer $\Gamma_{K}^{0 \rightarrow 2}$ is negative through the whole column within the ascending region, while positive values of $\Gamma_{A}^{0 \rightarrow 2}$ are located in the lower and middle troposphere (from 900 to $500 \mathrm{hPa}$ ). In the lower troposphere (below $700 \mathrm{hPa}$ ), there are positive values of $\Gamma_{K}^{1 \rightarrow 2}$ and $-b^{2}$ around the ascending area. That's to say, during Stage $\mathrm{I}$, the precipitation develops due to the KE transfer from the synoptic-scale window and a buoyancy conversion in the lower troposphere, and baroclinic instability in the middle troposphere.
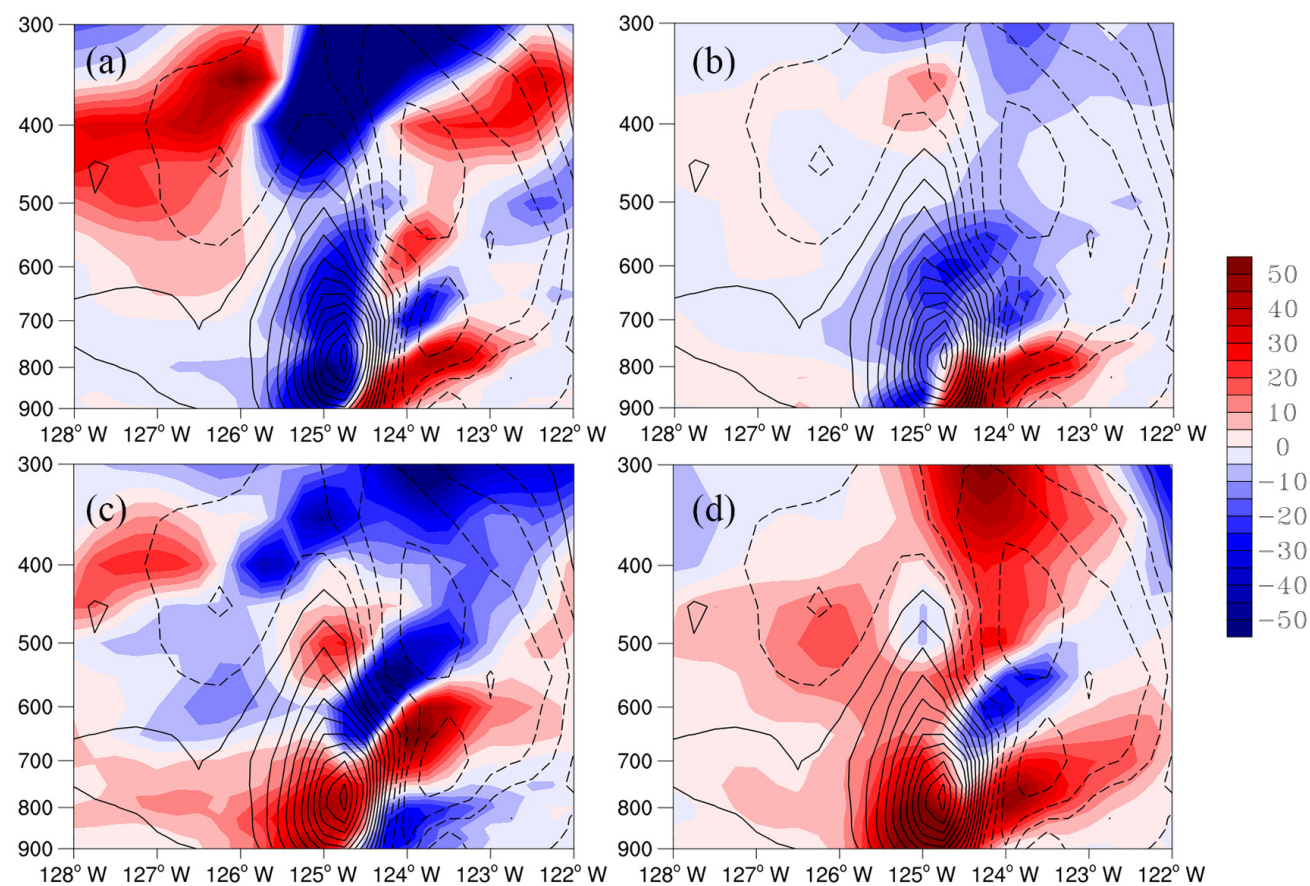

Figure 8. Vertical structures of energetics (shadings; in $10^{-4} \mathrm{~m}^{2} \mathrm{~s}^{-3}$ ) and mesoscale vertical velocity $\left(-\omega^{\sim 2}\right.$; contours; in $\left.\mathrm{Pa} / \mathrm{s}\right)$ averaged over the channel $42^{\circ}-44^{\circ} \mathrm{N}$ on 25 February at 10:00 UTC: (a) $\Gamma_{K}^{0 \rightarrow 2}$, (b) $\Gamma_{K}^{1 \rightarrow 2}$, (c) $\Gamma_{A}^{0 \rightarrow 2}$ and (d) $-b^{2}$. Solid contours stand for the ascending motion with an interval of 0.15 .

To explore the role of latent heating, we calculated $F_{L}^{2}$ on the mesoscale window as introduced in Section 2.2. Figure 9a displays the maps of $F_{L}^{2}$ averaged from 900 to $300 \mathrm{hPa}$ on 25 February at 10:00 UTC. The great positive values (shadings in Figure 9a) located near the Northern California correspond to the ascending motion (solid contours) in Stage I. 


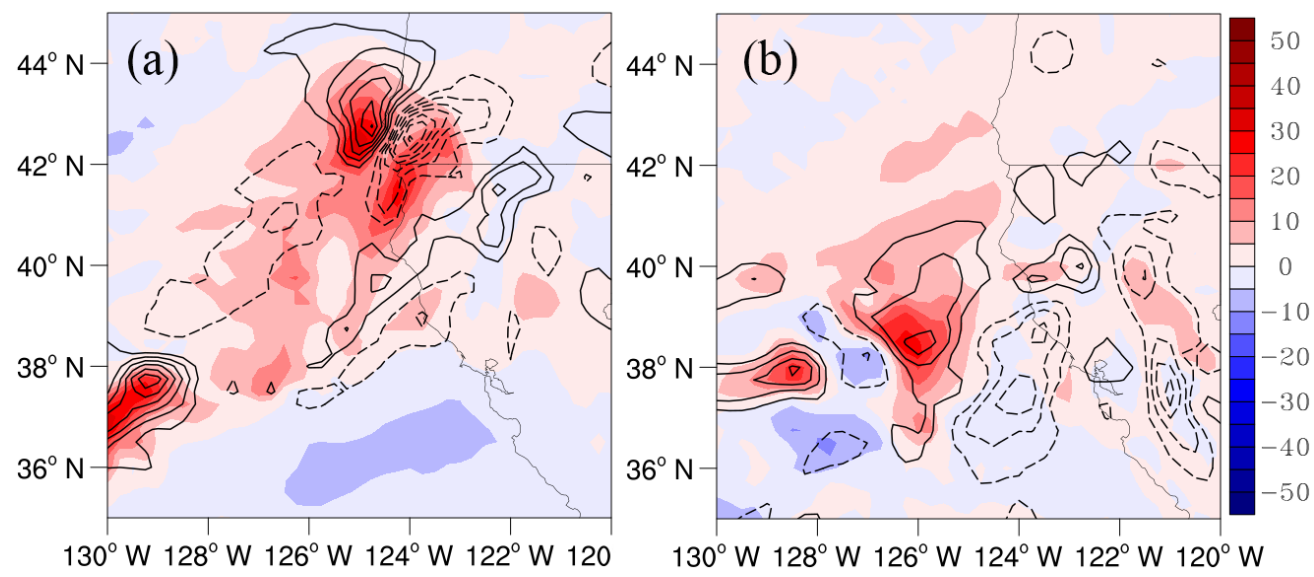

Figure 9. Maps of the latent heating term $F_{L}^{2}$ (shadings; in $\left.10^{-4} \mathrm{~m}^{2} \mathrm{~s}^{-3}\right)$ and vertical velocity $\left(-\omega^{\sim 2}\right.$; contours; in $\mathrm{Pa} / \mathrm{s}$ ) on the mesoscale window averaged vertically from 900 to $300 \mathrm{hPa}$ : (a) on 25 February at 10:00 UTC, (b) on 26 February at 18:00 UTC. Solid contours represent the ascending motion with an interval of 0.2 .

\subsection{Stage II}

Following the same procedure as above, we assessed the canonical transfers and buoyancy conversions for the processes during Stage II. Figure 10 shows spatial distributions of (a) $\Gamma_{K}^{0 \rightarrow 2}$, (b) $\Gamma_{K}^{1 \rightarrow 2}$, (c) $\Gamma_{A}^{0 \rightarrow 2}$, (d) $\Gamma_{A}^{1 \rightarrow 2}$, and (e) $-b^{2}$ at 18:00 UTC, 26 February averaged vertically from 900 to $300 \mathrm{hPa}$. The box in Figure 10a marks the rainfall region. Here, $\Gamma_{K}^{1 \rightarrow 2}$, $\Gamma_{A}^{0 \rightarrow 2}$ and $\Gamma_{A}^{1 \rightarrow 2}$ are negligible in the balance, and hence are not shown in the cross sections (Figure 11). It is clear that $\Gamma_{A}^{1 \rightarrow 2}$ and $-b^{2}$ are overall positive over the rainfall area (box in Figure 10a), though a few negative patches of $\Gamma_{K}^{0 \rightarrow 2}$ are identified. The zonal-vertical sectional distributions (averaged over the channel $38^{\circ}-40^{\circ} \mathrm{N}$ ) is presented in Figure 11. We can find that the main body of the ascending motion (solid contours) around $125^{\circ} \mathrm{W}$ develops upward to $300 \mathrm{hPa}$, slightly inclining to the west. In the middle troposphere (from 700 to $500 \mathrm{hPa}$ ), there are enhanced values of $\Gamma_{K}^{0 \rightarrow 2}$ and $-b^{2}$, corresponding to strong ascending motion. This means that, during Stage II, it is a barotropic instability and a buoyancy conversion in the middle layer that facilitate the development of the precipitation.

Like Stage I, the positive values of $F_{L}^{2}$ (shadings; Figure 9b) are consistent with strong ascending motion (solid contours) in Stage II, implying that there is a large amount of the latent heat release during the rainfall. 

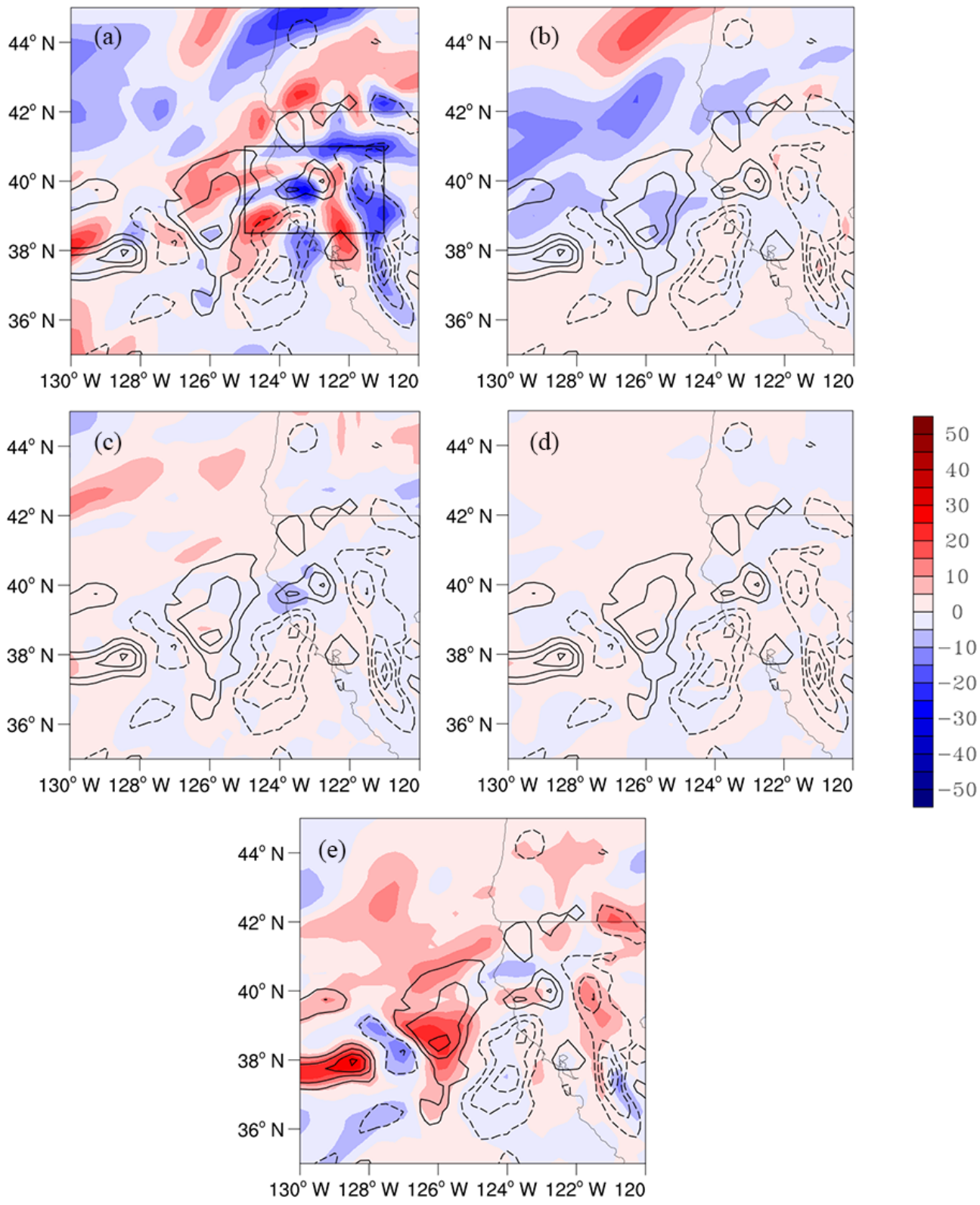

Figure 10. Maps of (a) $\Gamma_{K}^{0 \rightarrow 2}$ (shadings; in $10^{-4} \mathrm{~m}^{2} \mathrm{~s}^{-3}$ ), (b) $\Gamma_{K}^{1 \rightarrow 2}$ (shadings; in $10^{-4} \mathrm{~m}^{2} \mathrm{~s}^{-3}$ ), (c) $\Gamma_{A}^{0 \rightarrow 2}$ (shadings; in $10^{-4} \mathrm{~m}^{2} \mathrm{~s}^{-3}$ ), (d) $\Gamma_{A}^{1 \rightarrow 2}$ (shadings; in $10^{-4} \mathrm{~m}^{2} \mathrm{~s}^{-3}$ ) and (e) $-b^{2}$ (shadings; in $10^{-4} \mathrm{~m}^{2} \mathrm{~s}^{-3}$ ) averaged from 900 to $300 \mathrm{hPa}$ on 26 February at 18:00 UTC. The box in (a) denotes the rainfall area during Stage II. Contours of the mesoscale vertical velocity $\left(-\omega^{\sim 2}\right.$; in $\left.\mathrm{Pa} / \mathrm{s}\right)$ are superimposed with an interval of 0.2 (solid contours for the ascending motion). 

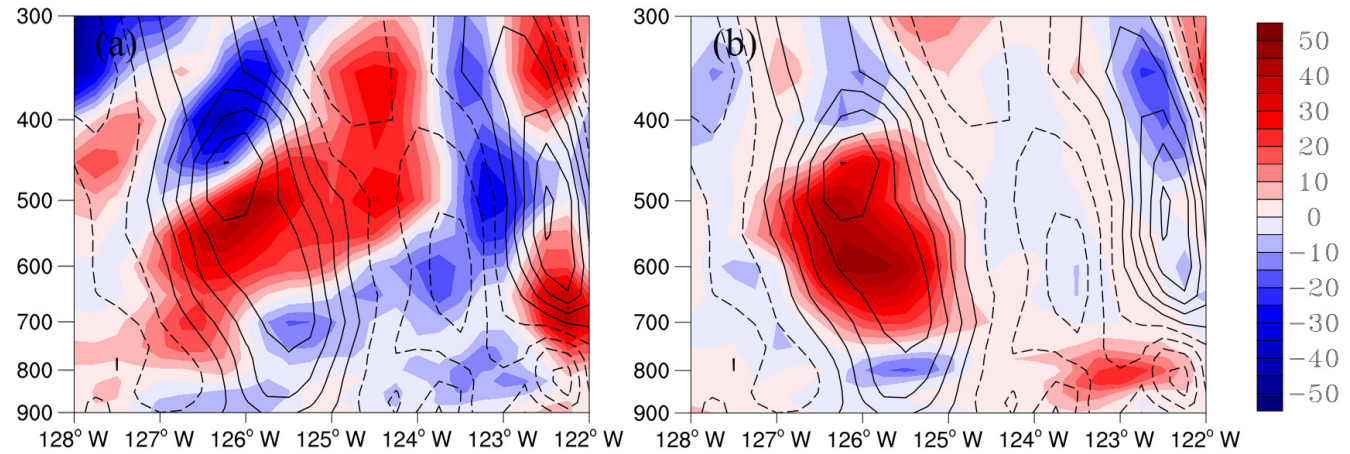

Figure 11. The zonal-vertical section of (a) $\Gamma_{K}^{0 \rightarrow 2}$ (shadings; in $10^{-4} \mathrm{~m}^{2} \mathrm{~s}^{-3}$ ) and (b) $-b^{2}$ (shadings; in $10^{-4} \mathrm{~m}^{2} \mathrm{~s}^{-3}$ ) averaged over the zonal band $38^{\circ}-40^{\circ} \mathrm{N}$ on 26 February at 18:00 UTC. Contours of the mesoscale vertical velocity $\left(-\omega^{\sim 2}\right.$; in $\mathrm{Pa} / \mathrm{s}$ ) are overlayed with an interval of 0.15 (solid contours for the ascending motion).

\subsection{Energy Pathway}

To understand the energy pathway for the rainstorm in question at two stages, we took volumetric averages of the energetics from $900 \mathrm{hPa}$ to $400 \mathrm{hPa}$ and over the rainfall areas respectively for Stage I (box in Figure 3a) and Stage II (box in Figure 3b). Then, the volume-averaged energetics were further averaged over time for the two respective stages. The resulting spatiotemporally averaged energetics are schematized in Figure 12, where an arrow stands for the direction of energy flow.

(a)

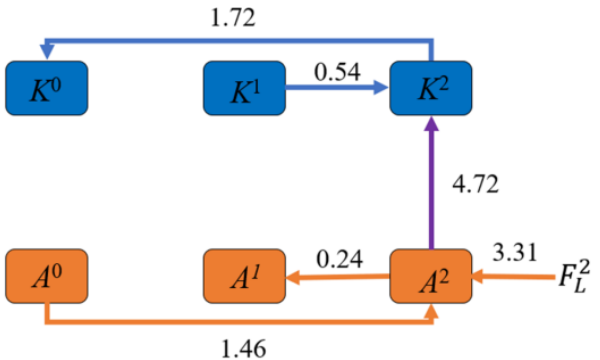

(b)

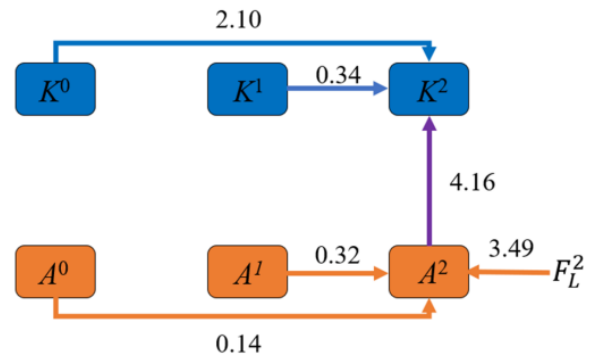

Figure 12. Schematics of the energy pathway for (a) Stage I and (b) Stage II. The energetics are in $10^{-4} \mathrm{~m}^{2} \mathrm{~s}^{-3}$. An arrow stands for the energy flow direction.

As we can see, during Stage I, the mesoscale APE $\left(A^{2}\right)$ is dominantly fueled by the latent heating $F_{L}^{2}$. Another source of $A^{2}$ is baroclinic instability which transfers APE from the background flow to the mesoscale window. As for the mesoscale $\mathrm{KE}\left(\mathrm{K}^{2}\right)$, it is obtained via buoyancy conversion, and is partly returned to the background flow.

For Stage II, the mesoscale window gains twice as much kinetic energy $\left(K^{2}\right)$ from the mesoscale APE reservoir via buoyancy conversion as it does from the background flow via barotropic instability. As for the APE balance, latent heating is the dominant source of the mesoscale $\mathrm{APE}\left(A^{2}\right)$ which then is converted to KE via buoyancy conversion.

\subsection{Comparison between Stage I and Stage II}

The similarity between the precipitation processes in Stage I and Stage II is that in both stages, latent heating and buoyancy conversion dominate in the energy balance. This may be attributed to the huge amount of latent heat release during the rainfall event. They can directly heat the atmosphere and produce APE, most of which is converted to KE via buoyancy conversion.

The differences between the rainfall energetics in the two stages are also obvious. Although the background flow contributes in both stages to the precipitation through instability, the dominant type of instability is different, with baroclinic instability occurring in Stage I while barotropic instability in Stage II. Considering the fact illustrated by Figure 12a 
that $\mathrm{KE}$ in Stage I is not obtained from but lost to the background flow, we conclude that the mesoscale $\mathrm{KE}\left(\mathrm{K}^{2}\right)$ is transferred to the background flow in Stage I, and is stored in there until Stage II, when it is released back to the mesoscale window again, triggering the heavy rainstorm. This may explain why the rainfall is slightly stronger in Stage II than in Stage I.

\section{Conclusions}

Using a recently-developed localized multiscale energetics analysis tool, we have investigated the dynamical processes underlying a heavy rainfall event in Northern California associated with the landfalling atmospheric river (AR) during 25-27 February 2019. Based on the trend of the hourly precipitation, the lifecycle of the rainstorm is divided into two stages: Stage I (from 25 February at 00:00 UTC to 26 February at 00:00 UTC) and Stage II (from 26 February at 12:00 UTC to 27 February at 12:00 UTC). In Stage I, the rainfall is located to the north of $40^{\circ} \mathrm{N}$, whereas in Stage II, it is moved to the south of the latitude. Moreover, the circulation pattern changes as time moves from Stage I to Stage II: during Stage I, the AR is closely related to an extratropical cyclone, while it is associated with another cyclone during Stage II.

Application of the multiscale window transform (MWT) allows the original fields to be reconstructed onto three scale windows, i.e., the background flow window (periods $>256 \mathrm{~h}$ ), the synoptic-scale window (periods of 32-256 h), and the mesoscale window (periods $<32 \mathrm{~h}$ ). On the synoptic-scale window, the AR and extratropical cyclone or anticyclone are well captured; on the mesoscale window, the enhanced mesoscale kinetic energy (KE) and the ascending motion coincide with large values of the hourly precipitation exceeding $5 \mathrm{~mm} / \mathrm{h}$. By diagnosing the interactions between the mesoscale window and the other two windows, dynamic mechanisms underlying the rainstorm are revealed.

In both stages, the latent heating and buoyancy conversion are found to play an important role. This implies that the latent heat release can heat the atmosphere and directly produce APE which is mostly converted to KE via buoyancy conversion. Additionally, it is found that the instability of the background flow also contributes to the development of the precipitation which is baroclinic in Stage I whereas barotropic in Stage II. The energy pathway reveals a connection between the two stages of precipitation. During Stage I, a part of the mesoscale KE is inversely transferred to and stored within the background flow, and, as time moves on to Stage II, it is released back to the mesoscale window, triggering the extremely heavy rainstorm during Stage II. This implies that the energy transfer across different scales ahead of the rainfall event should receive more attention since it may be the key factor for the prediction of precipitation.

So far, the multiscale interaction underlying the rainfall associated with the designated landfalling AR has been explored. It would be of interest to quantify how much precipitation is related to the synoptic scale flow and how much comes from the meso-scale process. This issue, among others, is to be investigated in the future studies.

Author Contributions: Conceptualization, X.S.L. and Z.Z.; methodology, X.S.L.; software, X.S.L.; validation, Z.Z.; formal analysis, X.S.L. and Z.Z.; investigation, X.S.L. and Z.Z.; resources, X.S.L.; data curation, Z.Z.; writing-original draft preparation, Z.Z.; writing-review and editing, X.S.L.; visualization, Z.Z.; supervision, X.S.L.; project administration, X.S.L.; funding acquisition, X.S.L. All authors have read and agreed to the published version of the manuscript.

Funding: This research was funded by the National Natural Science Foundation of China (Grant No. 41975064), and the 2015 Jiangsu Program for Innovation Research and Entrepreneurship Groups.

Institutional Review Board Statement: No applicable.

Informed Consent Statement: No applicable.

Data Availability Statement: The ERA5 data can be available at https: / cds.climate.copernicus.eu / cdsapp\#!/dataset/reanalysis-era5-pressure-levels?tab=overview (accessed on 10 September 2021). 
Acknowledgments: We are grateful to three anonymous reviewers for their constructive suggestions. Z. Z. thanks Yi-neng Rong for valuable suggestion and discussions.

Conflicts of Interest: The authors declare no conflict of interest.

\section{References}

1. Zhu, Y.; Newell, R.E. A Proposed Algorithm for Moisture Fluxes from Atmospheric Rivers. Mon. Weather Rev. 1998, 126, 725-735. [CrossRef]

2. Guan, B.; Waliser, D.E. Detection of Atmospheric Rivers: Evaluation and Application of an Algorithm for Global Studies. J. Geophys. Res. Atmos. 2015, 120, 12514-12535. [CrossRef]

3. Dettinger, M.D.; Ralph, F.M.; Das, T.; Neiman, P.J.; Cayan, D.R. Atmospheric Rivers, Floods and the Water Resources of California. Water 2011, 3, 445-478. [CrossRef]

4. $\quad$ Paltan, H.; Waliser, D.; Lim, W.H.; Guan, B.; Yamazaki, D.; Pant, R.; Dadson, S. Global Floods and Water Availability Driven by Atmospheric Rivers. Geophys. Res. Lett. 2017, 44, 10387-10395. [CrossRef]

5. Xiong, Y.; Ren, X. Influences of Atmospheric Rivers on North Pacific Winter Precipitation: Climatology and Dependence on ENSO Condition. J. Clim. 2021, 34, 277-292. [CrossRef]

6. Ralph, F.M.; Neiman, P.J.; Wick, G.A.; Gutman, S.I.; Dettinger, M.D.; Cayan, D.R.; White, A.B. Flooding on California's Russian River: Role of Atmospheric Rivers. Geophys. Res. Lett. 2006, 33, L13801. [CrossRef]

7. Neiman, P.J.; Ralph, F.M.; Wick, G.A.; Lundquist, J.D.; Dettinger, M.D. Meteorological Characteristics and Overland Precipitation Impacts of Atmospheric Rivers Affecting the West Coast of North America Based on Eight Years of SSM/I Satellite Observations. J. Hydrometeorol. 2008, 9, 22-47. [CrossRef]

8. Ralph, F.M.; Dettinger, M.D. Historical and National Perspectives on Extreme West Coast Precipitation Associated with Atmospheric Rivers during December 2010. Bull. Am. Meteorol. Soc. 2012, 93, 783-790. [CrossRef]

9. Guan, B.; Molotch, N.P.; Waliser, D.E.; Fetzer, E.J.; Neiman, P.J. The 2010/2011 Snow Season in California's Sierra Nevada: Role of Atmospheric Rivers and Modes of Large-scale Variability. Water Resour. Res. 2013, 49, 6731-6743. [CrossRef]

10. Lavers, D.A.; Villarini, G. The Nexus between Atmospheric Rivers and Extreme Precipitation across Europe. Geophys. Res. Lett. 2013, 40, 3259-3264. [CrossRef]

11. Kim, J.; Moon, H.; Guan, B.; Waliser, D.E.; Choi, J.; Gu, T.; Byun, Y. Precipitation Characteristics Related to Atmospheric Rivers in East Asia. Int. J. Climatol. 2021, 41, E2244-E2257. [CrossRef]

12. White, A.B.; Neiman, P.J.; Creamean, J.M.; Coleman, T.; Ralph, F.M.; Prather, K.A. The Impacts of California's San Francisco Bay Area Gap on Precipitation Observed in the Sierra Nevada during HMT and CalWater. J. Hydrometeorol. 2015, 16, 1048-1069. [CrossRef]

13. DeFlorio, M.J.; Waliser, D.E.; Guan, B.; Ralph, F.M.; Vitart, F. Global Evaluation of Atmospheric River Subseasonal Prediction Skill. Clim. Dyn. 2019, 52, 3039-3060. [CrossRef]

14. Pan, M.; Lu, M. A Novel Atmospheric River Identification Algorithm. Water Resour. Res. 2019, 55, 6069-6087. [CrossRef]

15. Pan, M.; Lu, M. East Asia Atmospheric River Catalog: Annual Cycle, Transition Mechanism and Precipitation. Geophys. Res. Lett. 2020, 47, e2020GL089477. [CrossRef]

16. Fu, G.; Liu, S.; Li, X.; Li, P.; Chen, L. Characteristics of Atmospheric Rivers over the East Asia in Middle Summers from 2001 to 2016. J. Ocean Univ. China 2021, 20, 235-243. [CrossRef]

17. Fu, G.; Liu, S.; Li, X.; Chen, L. Review on Atmospheric River Research. Period. Ocean Univ. China 2019, 49, 10-17. (In Chinese) [CrossRef]

18. Kim, J. Precipitation and Snow Budget Over the Southwestern United States During the 1994-1995 Winter Season in a Mesoscale Model Simulation. Water Resour. Res. 1997, 33, 2831-2839. [CrossRef]

19. Kamae, Y.; Mei, W.; Xie, S.-P. Climatological Relationship between Warm Season Atmospheric Rivers and Heavy Rainfall over East Asia. J. Meteorol. Soc. Jpn. 2017, 95, 411-431. [CrossRef]

20. Konrad, C.P.; Dettinger, M.D. Flood Runoff in Relation to Water Vapor Transport by Atmospheric Rivers Over the Western United States, 1949-2015. Geophys. Res. Lett. 2017, 44, 11456-11462. [CrossRef]

21. Trenberth, K. Atmospheric Moisture Recycling: Role of Advection and Local Evaporation. J. Clim. 1999, 12, 1368-1381. [CrossRef]

22. Trenberth, K.; Smith, L.; Qian, T.; Dai, A.; Fasullo, J. Estimates of the Global Water Budget and Its Annual Cycle Using Observational and Model Data. J. Hydrometeorol. 2007, 8, 758-769. [CrossRef]

23. Ralph, F.M.; Neiman, P.J.; Kiladis, G.N.; Weickmann, K.; Reynolds, D.W. A Multiscale Observational Case Study of a Pacific Atmospheric River Exhibiting Tropical-Extratropical Connections and a Mesoscale Frontal Wave. Mon. Weather Rev. 2011, 139, 1169-1189. [CrossRef]

24. Liang, X.S. Canonical Transfer and Multiscale Energetics for Primitive and Quasigeostrophic Atmospheres. J. Atmos. Sci. 2016, 73, 4439-4468. [CrossRef]

25. Liang, X.S.; Anderson, D.G.M. Multiscale Window Transform. Multiscale Model. Simul. 2007, 6, 437-467. [CrossRef]

26. Hersbach, H.; Bell, B.; Berrisford, P.; Hirahara, S.; Horányi, A.; Muñoz-Sabater, J.; Nicolas, J.; Peubey, C.; Radu, R.; Schepers, D.; et al. The ERA5 Global Reanalysis. Q. J. R. Meteorol. Soc. 2020, 146, 1999-2049. [CrossRef]

27. Lorenz, E.N. Available Potential Energy and the Maintenance of the General Circulation. Tellus 1955, 7, 157-167. [CrossRef] 
28. Shen, Y.; Sun, Y.; Liu, D.Y. Effect of Condensation Latent Heat Release on the Relative Vorticity Tendency in Extratropical Cyclones: A Case Study. Atmos. Ocean. Sci. Lett. 2020, 13, 275-285. [CrossRef]

29. Liang, X.S.; Robinson, A.R. Localized Multiscale Energy and Vorticity Analysis I. Fundamentals. Dyn. Atmos. Oceans 2005, 38, 195-230. [CrossRef]

30. Liang, X.S.; Robinson, A.R. Localized Multi-Scale Energy and Vorticity Analysis II. Finite-Amplitude Instability Theory and Validation. Dyn. Atmos. Oceans 2007, 44, 51-76. [CrossRef]

31. Xu, F.; Liang, X.S. The Synchronization between the Zonal Jet Stream and Temperature Anomalies Leads to an Extremely Freezing North America in January 2019. Geophys. Res. Lett. 2020, 47, e2020GL089689. [CrossRef]

32. Zhao, Y.-B.; Liang, X.S. On the Inverse Relationship between the Boreal Wintertime Pacific Jet Strength and Storm-Track Intensity. J. Clim. 2018, 31, 9545-9564. [CrossRef]

33. Ma, J.; Liang, X.S. Multiscale Dynamical Processes Underlying the Wintertime Atlantic Blockings. J. Atmos. Sci. 2017, 74, 3815-3831. [CrossRef]

34. Xu, F.; Liang, X.S. Drastic Change in Dynamics as Typhoon Lekima Experiences an Eyewall Replacement Cycle. Front. Earth Sci. 2021, 1-11. [CrossRef]

35. Rong, Y.-N.; Ma, J.; Li, Y.; Liang, X.S. On the Multiscale Dynamics of a Top-down Developing Vortex over Tibet Plateu. Adv. Meteorol. Sci. Technol. 2021, 11, 7-18. (In Chinese) [CrossRef]

36. Yang, Y.; Liang, X.S. New Perspectives on the Generation and Maintenance of the Kuroshio Large Meander. J. Phys. Oceanogr. 2019, 49, 2095-2113. [CrossRef]

37. Rutz, J.J.; Steenburgh, W.J.; Ralph, F.M. Climatological Characteristics of Atmospheric Rivers and Their Inland Penetration over the Western United States. Mon. Weather Rev. 2014, 142, 905-921. [CrossRef]

38. Ralph, F.M.; Rutz, J.J.; Cordeira, J.M.; Dettinger, M.; Anderson, M.; Reynolds, D.; Schick, L.J.; Smallcomb, C. A Scale to Characterize the Strength and Impacts of Atmospheric Rivers. Bull. Am. Meteorol. Soc. 2019, 100, 269-289. [CrossRef]

39. Newell, R.E.; Newell, N.E.; Zhu, Y.; Scott, C. Tropospheric Rivers?-A Pilot Study. Geophys. Res. Lett. 1992, 19, 2401-2404. [CrossRef]

40. Ralph, F.M.; Neiman, P.J.; Wick, G.A. Satellite and CALJET Aircraft Observations of Atmospheric Rivers over the Eastern North Pacific Ocean during the Winter of 1997/98. Mon. Weather Rev. 2004, 132, 1721-1745. [CrossRef]

41. Torrence, C.; Compo, G.P. A Practical Guide to Wavelet Analysis. Bull. Am. Meteorol. Soc. 1998, 79, 61-78. [CrossRef]

42. Gimeno, L.; Nieto, R.; VÃ jzquez, M.; Lavers, D.A. Atmospheric Rivers: A Mini-Review. Front. Earth Sci. 2014, 2, 1-6. [CrossRef] 